\title{
Modeling of Dimmable Fluorescent Lamp Including the Tube Temperature Effects
}

\author{
Deyan Lin, Member, IEEE, Wei Yan, Member, IEEE, and S. Y. R. Hui, Fellow, IEEE
}

\begin{abstract}
This paper presents an improved semitheoretical fluorescent lamp model by including the effect of the lamp tube temperature on the lamp electrical parameters at different dimming levels. The experimental results have verified that the lamp tube temperature is a linear function of the lamp's input power and has significant influence on the lamp's electrical parameters during the dimming process. The comparison on the simulation and measurements shows that the improved lamp model can predict the lamp electrical characteristics accurately in a wide dimming range under both low- and high-frequency operations.
\end{abstract}

Index Terms-Ballasts, dimming, fluorescent lamp modeling, lighting.

\section{INTRODUCTION}

$\mathbf{E}$ LECTROMAGNETIC ballasts have regained attention because new magnetic materials can reduce the core loss and enable the magnetic ballasts to be energy-saving and environmentally friendly products [1], [2]. A more accurate and reliable lamp model that can predict the lamp electrical terminal characteristics at the mains (e.g., $50 \mathrm{~Hz}$ ) operating frequency becomes necessary for ballast designers to have a better understanding of the lamp behaviors. A variety of fluorescent lamp models has been proposed so far [3]-[20]. These models are usually suitable for lamps operated at high frequency only and are not applicable for lamps under dimming conditions. To cope with a wide range of general applications, it is necessary to have an improved lamp model that can predict the lamp electrical characteristics at different operating frequencies and under different dimming conditions.

The authors have previously proposed a semitheoretical fluorescent lamp model [20] which can predict the lamp electrical characteristics accurately under different operating frequencies and transient states. However, this model does not consider the influence of the lamp tube temperature on the lamp behavior.

Manuscript received March 10, 2010; revised July 6, 2010; accepted November 19, 2010. Date of publication December 17, 2010; date of current version August 12, 2011. This work was supported by the Research Grants Council of the Hong Kong Special Administrative Region, China, under Project 9041162 (CityU 122606)

D. Y. Lin is with the City University of Hong Kong, Kowloon, Hong Kong, and also with Jianghan University, Wuhan 430010, China.

W. Yan is with the Center for Power Electronics, Department of Electronic Engineering, City University of Hong Kong, Kowloon, Hong Kong.

S. Y. R. Hui is with the Center for Power Electronics, Department of Electronic Engineering, City University of Hong Kong, Kowloon, Hong Kong, and also with the Department of Electrical and Electronic Engineering, Imperial College London, SW7 2AZ London, U.K. (e-mail: eeronhui@cityu.edu.hk; r.hui@imperial.ac.uk).

Color versions of one or more of the figures in this paper are available online at http://ieeexplore.ieee.org.

Digital Object Identifier 10.1109/TIE.2010.2100333
Although the fluorescent lamp is sometimes known as a "cold light source" (when compared with high-intensity-discharge lamps), the total input power still causes ohmic heating that heats up the tube temperature well above the room temperature. For example, it has been pointed out that over $70 \%$ of the input power of fluorescent lamps is dissipated as heat [23]. The tube temperature should have different values under different input lamp power. Therefore, to accurately predict the lamp characteristics, one should include the effect of the lamp tube temperature on the lamp parameters at different dimming levels. This paper presents a new approach to improve the semitheoretical fluorescent lamp model in [20] by including the effect of the lamp tube temperature. It is an improved version of [24]. The simulated and experimental results in this paper clearly confirm that, after considering the effect of the lamp tube temperature, the lamp model becomes more accurate than before in simulating the electrical characteristics of the lamp. The improved lamp model can be used in the design for both dimmable magnetic ballast and dimmable electronic ballast fluorescent lamp systems [25].

\section{Model Implementation}

As illustrated in [20] and [21], the fluorescent lamp model consists of five physical and circuit equations as follows:

$$
\begin{aligned}
\frac{d T_{e}}{d t} & =a_{1}\left(i^{2} R-P_{\text {con }}-P_{\text {rad }}\right) \\
P_{\text {rad }} & =a_{2} \exp \left(-e a_{3} / k T_{e}\right) \\
P_{\text {con }} & =a_{4}\left(T_{e}-T_{0}\right) \\
R & =a_{5} T_{e}^{-3 / 4} \exp \left(e a_{6} / 2 k T_{e}\right) \\
V(t) & =a_{7} L \frac{d i}{d t}+i(R+r)+v_{\text {ele }} .
\end{aligned}
$$

The model parameters in the aforementioned equations and their definitions are listed in Table I.

The adjustable model constants $a_{1}, \ldots, a_{7}$ can be searched by a special optimal search method, such as the genetic algorithm (GA), based on experimental lamp current and lamp voltage waveforms measured at $50 \mathrm{~Hz}$. After the adjustable model constants are determined at $50 \mathrm{~Hz}$, the lamp model can be applied to both magnetic ballast circuits and electronic ballast circuits as shown in Fig. 1.

The lamp model in [20] and [21] assumes that $T_{0}$ (lamp tube temperature) in the model equation (3) is a constant value. This assumption is only valid when the lamp is operated under fullpower condition. When the lamp is operated under the dimming conditions, the lamp power is lower than that under the fullpower state. Thus, the lamp tube temperature as a function of 
TABLE I

Definition OF THE Model Parameters

\begin{tabular}{|l|l|}
\hline Symbol & Definition \\
\hline$T_{e}$ & electron temperature \\
\hline$i$ & lamp current \\
\hline$i^{2} R$ & input power to the lamp \\
\hline$P_{c o n}$ & thermal conduction loss \\
\hline$P_{\text {rad }}$ & radiation loss \\
\hline$T_{0}$ & tube temperature \\
\hline$k$ & Boltzmann constant \\
\hline$e$ & charge on an electron \\
\hline$V(\mathrm{t})$ & power supply voltage \\
\hline$L$ & ballast inductance \\
\hline$r$ & ballast resistance \\
\hline$V_{\text {ele }}$ & electrode voltage drop \\
\hline$a_{l}, \ldots, a_{7}$ & adjustable model constants \\
\hline
\end{tabular}

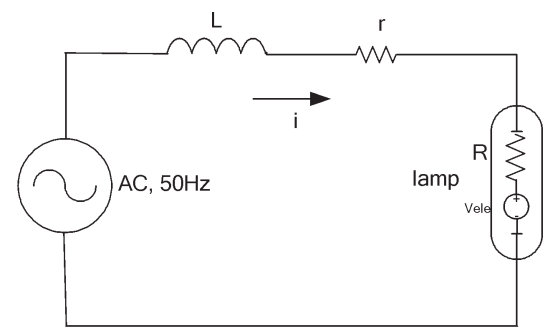

(a)

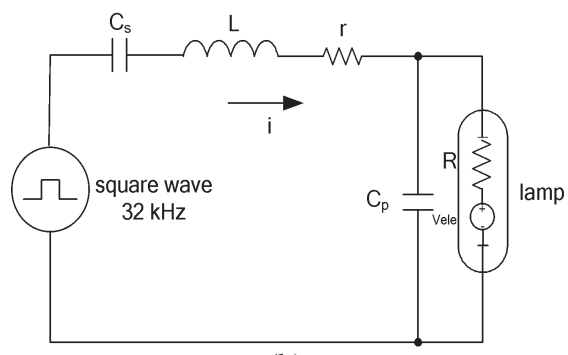

(b)

Fig. 1. Fluorescent lamp power supply circuit diagram. (a) 50-Hz driving circuit. (b) High-frequency driving circuit.

the lamp power should be lower than that in the full-power state. In order to find out the quantitative relationship between the lamp tube temperature and the input power in a fluorescent lamp, the lamp tube temperature at different dimming levels and at different tube locations has been measured by a temperature measurement system-Agilent 34970A data acquisition/switch unit with a $34901 \mathrm{~A}$ multiplexer data processing system as shown in Fig. 2. The temperature sensors of the data processing system are attached at five different locations on the lamp tube surface as shown in Fig. 3. Among these sensors, $S_{1}$ and $S_{5}$ are attached in the locations of lamp filaments where the temperature values are the highest. Sensors $\mathrm{S}_{2}$ and $\mathrm{S}_{4}$ are located in the two ends of the tube, which are close to the filaments. $S_{3}$ is located in the middle of the tube. A T8 18-W fluorescent lamp (PHILIPS LIFEMAX TLD 18W/54-765 COOL DAYLIGHT) and a T8 36-W fluorescent lamp (PHILIPS LIFEMAX TLD 36W/54-765 COOL DAYLIGHT) are used as examples in this paper. The temperature values were recorded each time after the lamp had been adjusted into a new power level for $30 \mathrm{~min}$. The measured tube temperature rise values with respect to room temperature at $24{ }^{\circ} \mathrm{C}$ for two different types of fluorescent lamps are shown in Figs. 4 and 5.

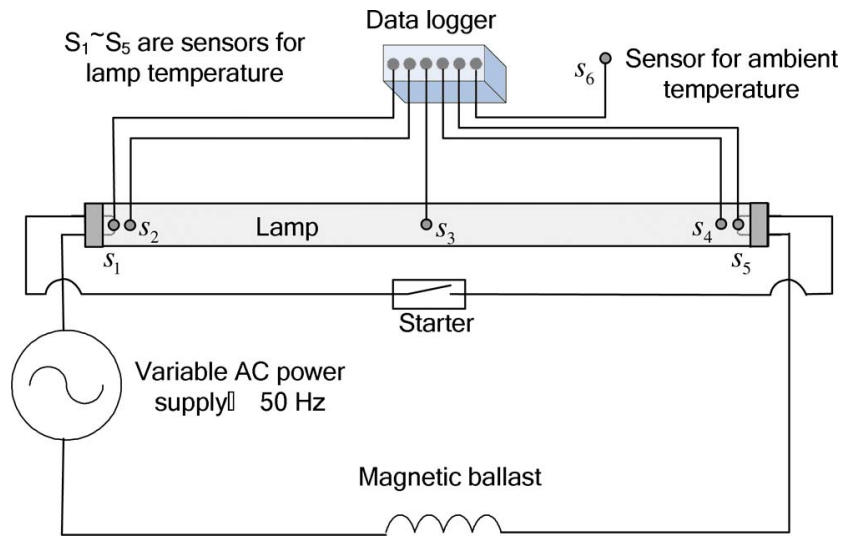

Fig. 2. Diagram of tube temperature measuring system.

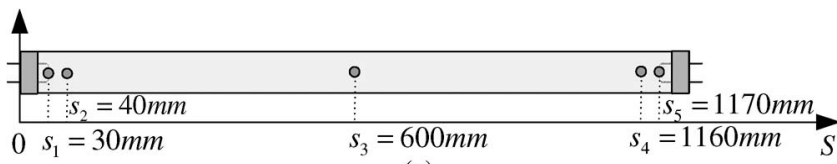

(a)

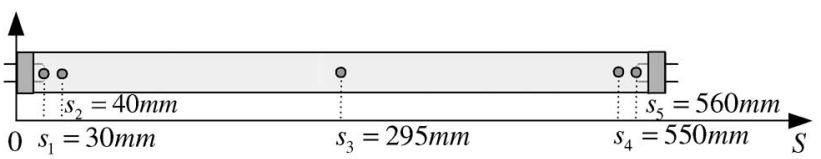

(b)

Fig. 3. Layout of temperature sensors. (a) T8 36-W fluorescent lamp. (b) T8 18-W fluorescent lamp.

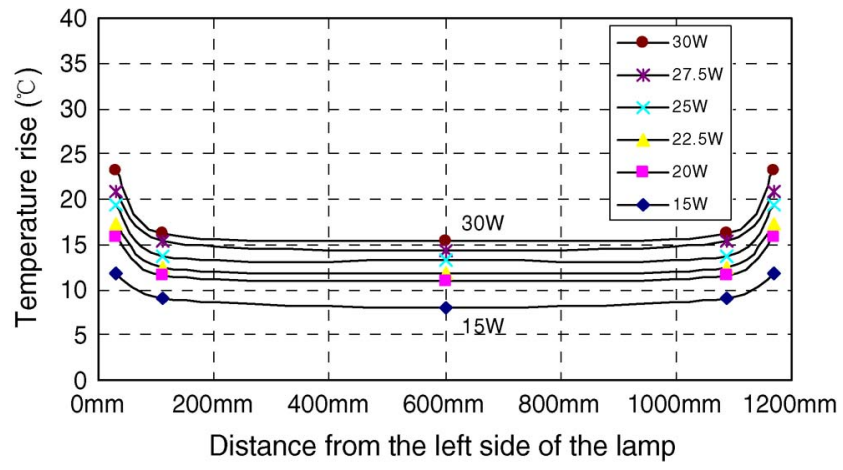

(a)

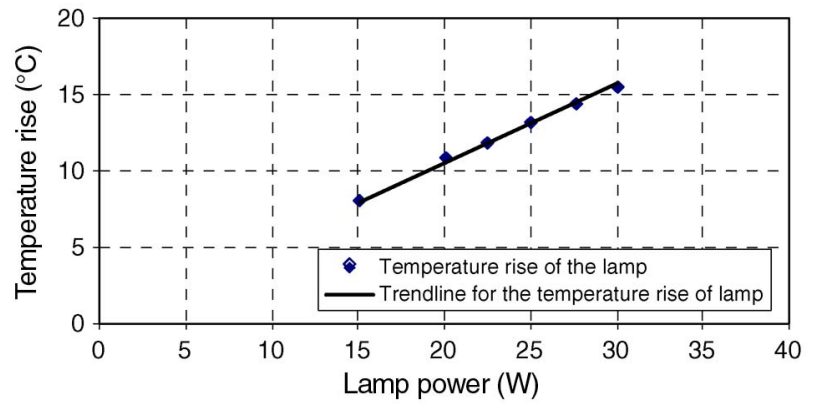

(b)

Fig. 4. Measured tube temperature rise of a T8 36-W fluorescent lamp at room temperature of $24^{\circ} \mathrm{C}$. (a) Lamp tube temperature rise at different points of the tube under different dimming levels (T8 36-W lamp). (b) Variation of the lamp temperature rise in the middle of the tube with the lamp power (T8 36-W lamp).

From the curves in both Figs. 4(a) and 5(a), one can observe three facts: 1) the tube temperature is a function of the measuring points along the tube; 2 ) the temperature at any location 


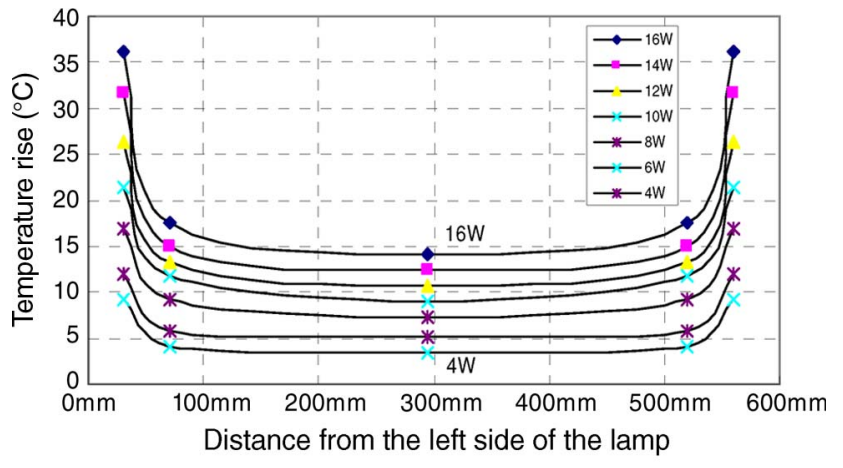

(a)

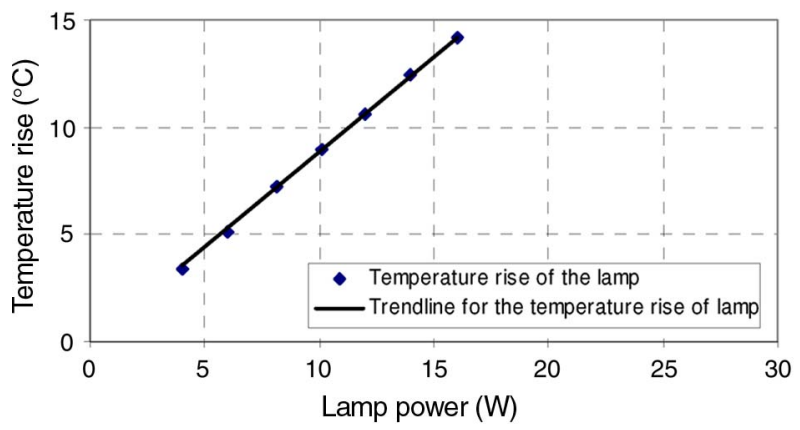

(b)

Fig. 5. Measured tube temperature rise of a T8 18-W fluorescent lamp at room temperature of $24^{\circ} \mathrm{C}$. (a) Lamp tube temperature rise at different points of the tube under different dimming levels (T8 18-W lamp). (b) Variation of the lamp tube temperature rise in the middle of the tube with the lamp power (T8 18-W lamp).

of the tube is the function of the total input power; and 3) the relationship between the tube temperature and the total input power at any location of the tube is a linear function, which can be expressed by the relationship in the following equation:

$$
T_{0}=T_{a}+a_{8} i^{2} R
$$

where $T_{a}$ is the ambient temperature and $a_{8}$ is a new adjustable constant introduced to the proposed model.

The simplified semitheoretical fluorescent lamp model reported in [20] is a 1-D lamp model, which assumes that the lamp tube temperature is constant. Figs. 4(b) and 5(b) clearly show that this assumption is not correct. In this paper, the introduction of the lamp tube temperature equation (6) can solve this problem. The new improved semitheoretical fluorescent lamp model consists of six equations from (1) to (6), which have a total of eight adjustable model constants. These adjustable constants can be searched by using a GA program and with the help of one set of measured lamp current and voltage waveforms at a $50-\mathrm{Hz}$ operating frequency. The GA approach used in [20]-[22] is also used here to search for the optimum solutions for the following optimum problem:

$$
J\left(a_{1}, \ldots, a_{8}\right)=\min \left[\sum\left(V_{i}-V_{i}^{*}\right)^{2}+\sum\left(I_{i}-I_{i}^{*}\right)^{2}\right]
$$

where $\left(a_{1}, \ldots, a_{8}\right) \in S, V_{i}$ and $I_{i}$ are simulated voltage and current values; $V_{i}^{*}$ and $I_{i}^{*}$ are sampled voltage and current values from the experimental measurement at $50 \mathrm{~Hz}$, and $S$ is the potential solution space. A set of $\left\{a_{1} \ldots a_{8}\right\}$ should be searched in a space of potential solutions so that the right side of (7) will be minimized.
TABLE II

Adjustable Model Constants for Different Types of LAmps

\begin{tabular}{|c|c|c|c|c|c|c|c|c|}
\hline Lamp & $a 1$ & $a 2$ & $a 3$ & $a 4$ & $a 5$ & $a 6$ & $a 7$ & $a 8$ \\
\hline T8 18W & 75503.5 & 143198.9 & 2.409 & 0.040 & 1984.24 & 0.276 & 1.634 & 0.918 \\
\hline T8 36W & 40225.4 & 119381.6 & 4.669 & 0.062 & 6529.46 & 0.264 & 1.232 & 0.683 \\
\hline
\end{tabular}

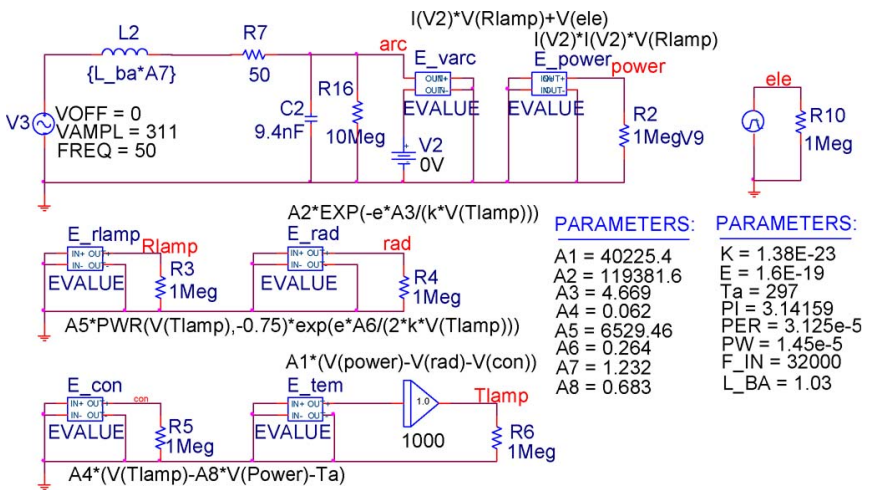

Fig. 6. PSpice model for 36-W fluorescent lamp at $50 \mathrm{~Hz}$.

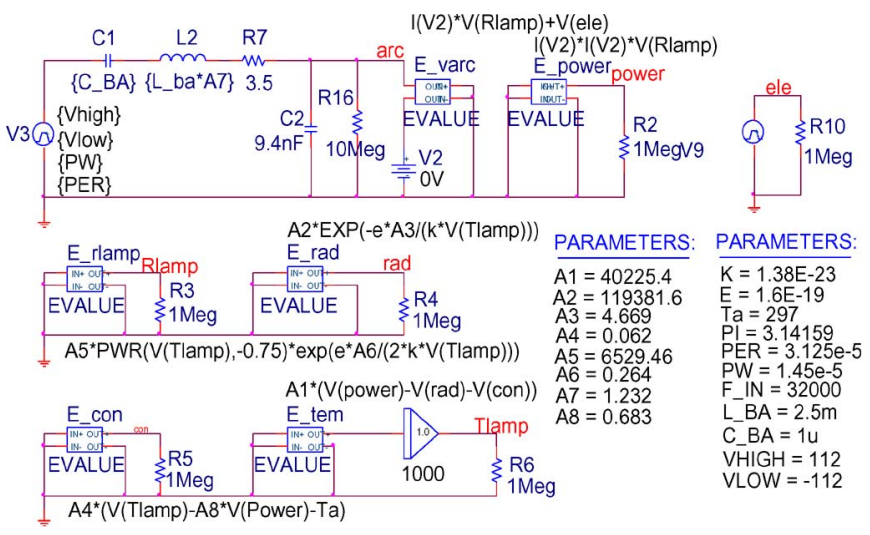

Fig. 7. PSpice model for $\mathrm{T} 8 \mathrm{36}-\mathrm{W}$ fluorescent lamp at high frequency.

The proposed lamp model has been applied to a T8 18-W fluorescent lamp (PHILIPS LIFEMAX TLD 18W/54-765 COOL DAYLIGHT) and a T8 36-W fluorescent lamp (PHILIPS LIFEMAX TLD 36W/54-765 COOL DAYLIGHT). Experimental measurements for lamp voltage and lamp current were obtained with these lamps driven by a low-frequency $(50-\mathrm{Hz})$ magnetic ballast as shown in Fig. 1(a). Eight adjustable model constants are determined by the GA, based on the sampled lamp voltage and lamp current values extracted from $50-\mathrm{Hz}$ experimental data. The optimal model constants are shown in Table II.

\section{Simulation Results And EXPERIMENTAL VERIFICATION}

Two PSpice circuit models for the T8 36-W fluorescent lamp operated at $50 \mathrm{~Hz}$ and high frequencies are developed as shown in Figs. 6 and 7, respectively. With these models, one can easily simulate the electrical characteristics of fluorescent lamps at any operating frequencies and under different dimming levels.

The simulated and experimental voltage and current waveforms for the T8 18-W fluorescent lamp operated at a $100 \%$ rated lamp power and a 35\% rated lamp power are shown in Figs. 8 and 9, respectively, when the lamp operating frequency 


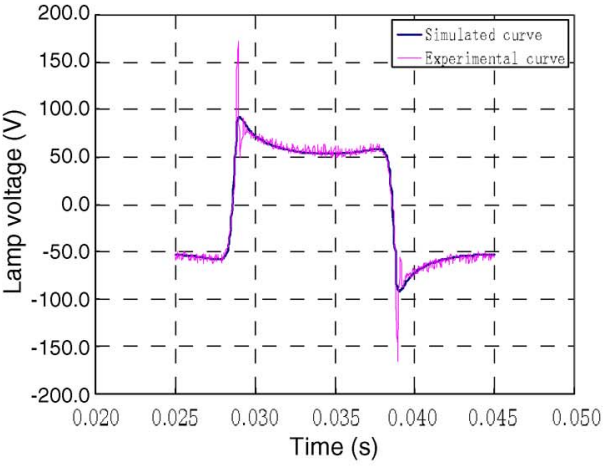

(a)

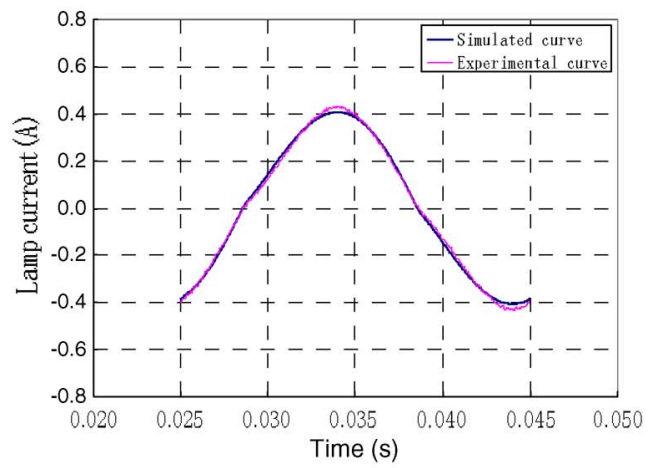

(b)

Fig. 8. Simulated and experimental lamp voltage and current waveforms of T8 18-W fluorescent lamp at 50-Hz operating frequency and $100 \%$ of rated lamp power. (a) Simulated and experimental lamp voltage waveforms. (b) Simulated and experimental lamp current waveforms.

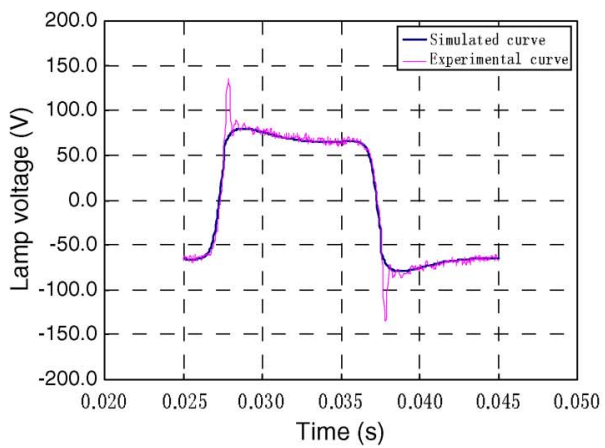

(a)

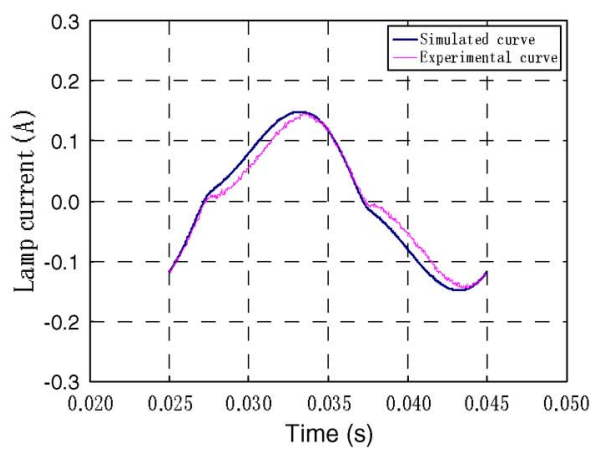

(b)

Fig. 9. Simulated and experimental lamp voltage and current waveforms of T8 18-W fluorescent lamp at 50-Hz operating frequency and 35\% of rated lamp power. (a) Simulated and experimental lamp voltage waveforms. (b) Simulated and experimental lamp current waveforms.

TABLE III

RELATIONSHIP OF THE INPUT AC Voltage AND THE Relative Lamp Power IN Dimming Process

\begin{tabular}{|l|c|c|c|c|c|c|}
\hline $\begin{array}{l}\text { Input ac } \\
\text { voltage (V) }\end{array}$ & $220 \mathrm{~V}$ & $193 \mathrm{~V}$ & $179 \mathrm{~V}$ & $173 \mathrm{~V}$ & $109 \mathrm{~V}$ & $99 \mathrm{~V}$ \\
\hline $\begin{array}{l}\text { Lamp power } \\
\text { /Rated lamp } \\
\text { power \% }\end{array}$ & $100 \%$ & $85 \%$ & $80 \%$ & $75 \%$ & $35 \%$ & $25 \%$ \\
\hline
\end{tabular}

is $50 \mathrm{~Hz}$. It can be seen that, after the lamp tube temperature has been taken into consideration, the simulation results are closer to the experimental results at different dimming levels in a low-frequency range. To verify the improvement of the new model in simulating lamp electrical characteristics under dimming conditions, a comparison study has been carried out for simulation results generated by different lamp models (with or without adjustable constant $a_{8}$ ). Dimming is controlled by varying the input ac voltage. The relationship of the input voltage and the lamp power is shown in Table III. The simulation errors caused by different lamp models are calculated by the following equations:

$$
\begin{aligned}
& \operatorname{error}\left(V_{\text {lamp }}\right)=\sum_{i=1}^{N} \frac{a b s\left(V_{i}-V_{i}^{*}\right)}{a b s\left(V_{i}^{*}\right)} \\
& \operatorname{error}\left(I_{\text {lamp }}\right)=\sum_{i=1}^{N} \frac{a b s\left(I_{i}-I_{i}^{*}\right)}{a b s\left(I_{i}^{*}\right)}
\end{aligned}
$$

where $i$ is the number of the sampled voltage or current, $V_{i}$ and $I_{i}$ are simulated lamp voltage and current values, $V_{i}^{*}$ and $I_{i}^{*}$ are sampled experimental lamp voltage and lamp current values, and $N$ is the total sampling number. The comparison of the simulated voltage and current waveforms of a T8 18-W fluorescent lamp (PHILIPS LIFEMAX TLD 18W/54-765 COOL DAYLIGHT) by different lamp models is shown in Fig. 10. The comparison of accumulated simulation errors using new (with $a_{8}$ ) and old (without $a_{8}$ ) models is shown in Fig. 11. It can be found from Figs. 10 and 11 that the new model reduces the simulation errors in both the simulated lamp voltage and lamp current waveforms under dimming conditions, particularly when the lamp power is dimmed down to $35 \%$ and $25 \%$ rated lamp power.

Simulated and experimental lamp voltage and lamp current waveforms for the $\mathrm{T} 8 \mathrm{36}-\mathrm{W}$ fluorescent lamp operated at $100 \%, 80 \%$, and $60 \%$ of the rated lamp power are shown in Figs. 12-14, respectively, when the operating frequency of the lamp was $50 \mathrm{~Hz}$.

The same set of model constants has been applied to the T8 $36-\mathrm{W}$ fluorescent lamp driven by a high-frequency $(32-\mathrm{kHz})$ electronic ballast shown in Fig. 1(b). The results between the simulated waveforms and experimental waveforms at different dimming levels are shown in Figs. 15 (100\%), 16 (70\%), and $17(45 \%)$. It can be seen that the simulated results are very close to the measurements. 

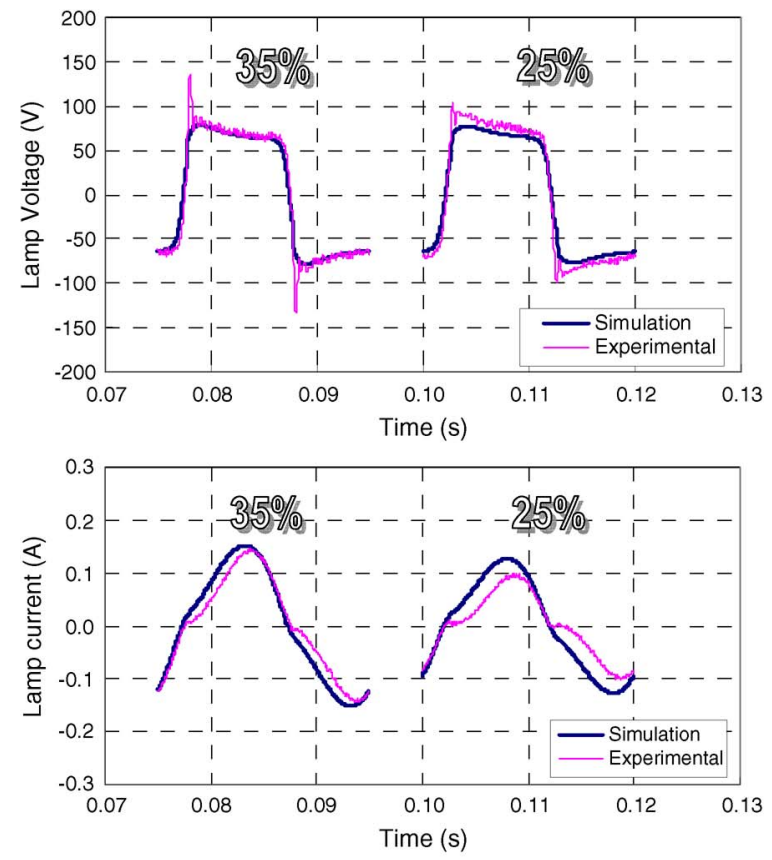

(a)
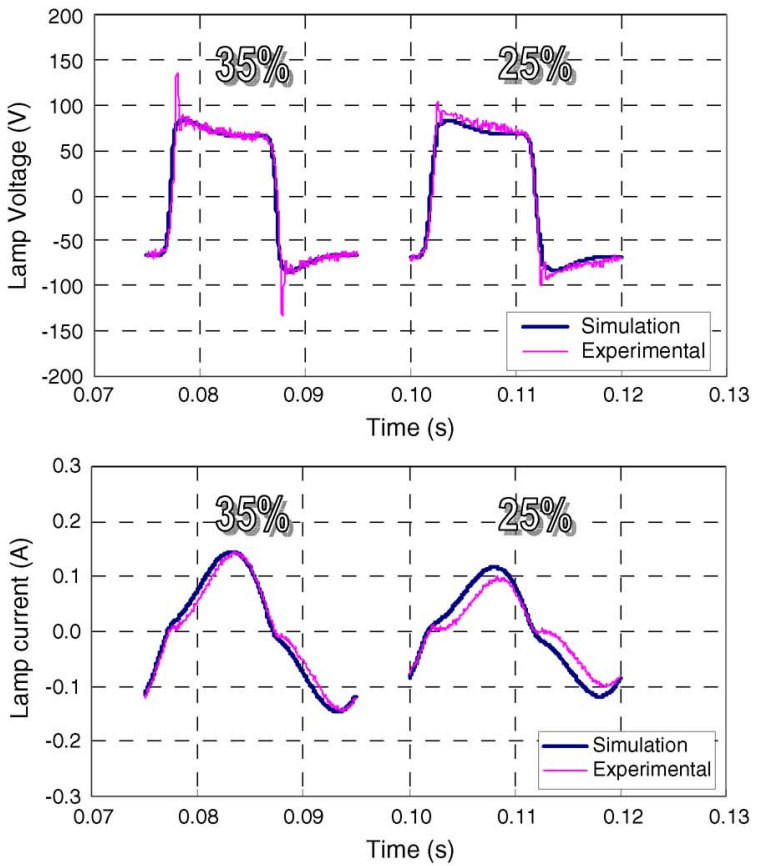

(b)

Fig. 10. Comparison of simulation results for old model (without $a_{8}$ ) and new model (with $a_{8}$ ) when the T8 18-W lamp was dimmed down to 35\% and 25\% of the rated power, respectively. (a) Simulated lamp voltage and current results using the model without adjustable constant $a_{8}$ when the lamp was dimmed down. (b) Simulated lamp voltage and current results using the model with adjustable constant $a_{8}$ when the lamp was dimmed down.

\section{Discussion AND CONCLUSION}

The lamp tube temperature is a linear function of the total lamp input power, and it influences the lamp's electrical parameters during the lamp dimming process. After taking into account the effect of the tube temperature on the lamp electrical parameters, the improved fluorescent lamp model can reduce the simulation errors and accurately predict the electrical characteristics of different types of fluorescent lamps under

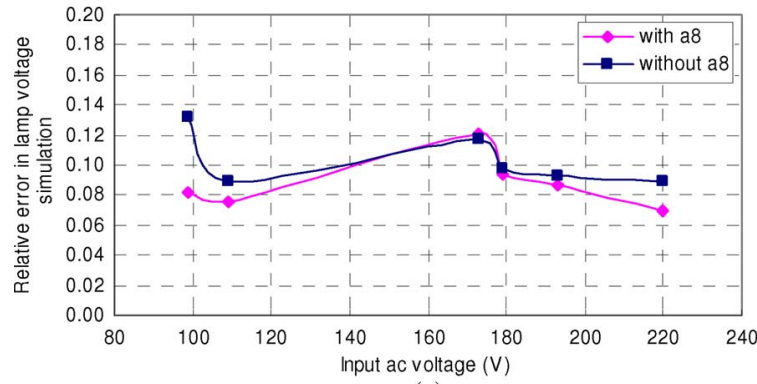

(a)

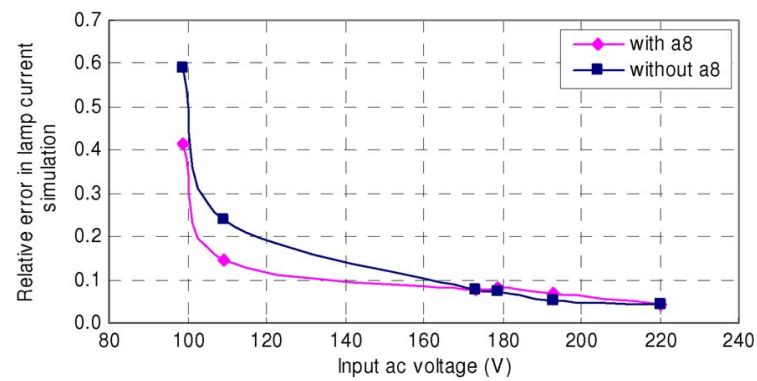

(b)

Fig. 11. Comparison of accumulated relative errors for old model (without $a_{8}$ ) and new model (with $a_{8}$ ) when the input ac voltage reduced from 220 to $99 \mathrm{~V}$ at $50 \mathrm{~Hz}$. (a) Accumulated relative error in lamp voltage simulation. (b) Accumulated relative error in lamp current simulation.

different dimming levels and at different operating frequencies. All model constants in the six model equations can be searched by the GA based on simple measurements of the lamp voltage and current at $50-\mathrm{Hz}$ operation. This model can be easily adapted into any computer-aided design software, such as PSpice shown in this paper, for ballast circuit designers to design both magnetic and electronic ballasts. It can provide accurate predictions of voltage and current waveforms in the ballast simulation, particularly for dimmable magnetic ballasts.

From the comparison presented earlier, one can see that the simulation results are much better when the new model constant $a_{8}$ is introduced into the lamp model. However, the simulated lamp current still has relatively high accumulated error when the dimming power reaches to $25 \%$ for the T8 $18-\mathrm{W}$ fluorescent lamp and $45 \%$ for the T8 36-W fluorescent lamp. There are two possible reasons to explain the simulation error. The first possible reason is that the voltage of the ac source is too low to reignite the lamp discharge at the beginning of each half cycle. When the lamp current changes its polarity in each half cycle, a high electric field is required for building up new electron density to compensate those decayed fast to the wall by diffusion and recombination during the zero current period. If this requirement cannot be met, the lamp will fail to be reignited. It is obvious that, at a $25 \%$ lamp power, the ac source voltage is at the critical point to reignite the lamp. It takes quite a long time to reignite the lamp. Therefore, the lamp current remains at a very low value for quite a long time. This critical reignition process has not yet been taken into consideration in the lamp model. The second possible reason follows the first reason. Caused by the delay of the lamp reignition, the measured lamp current is less sinusoidal than the simulated one. In the simulation, the influence of the nonlinear magnetic core behavior of the practical magnetic ballast is not included. However, in the proposed model, we assume that the impedance 


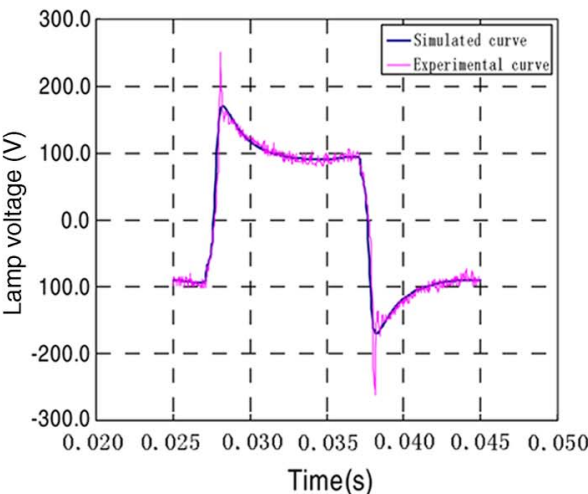

(a)

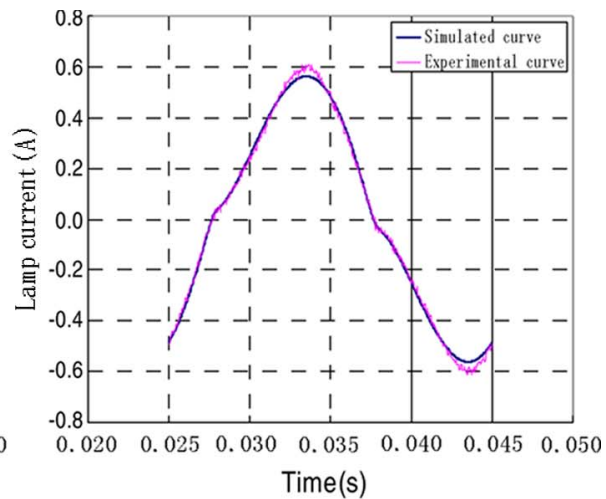

(b)

Fig. 12. Simulated and experimental lamp voltage and current waveforms of T8 36-W fluorescent lamp at 50-Hz operating frequency and $100 \%$ of rated lamp power. (a) Simulated and experimental lamp voltage waveforms. (b) Simulated and experimental lamp current waveforms.

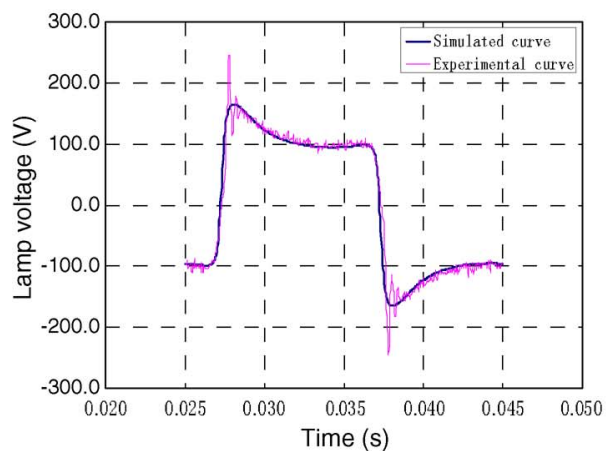

(a)

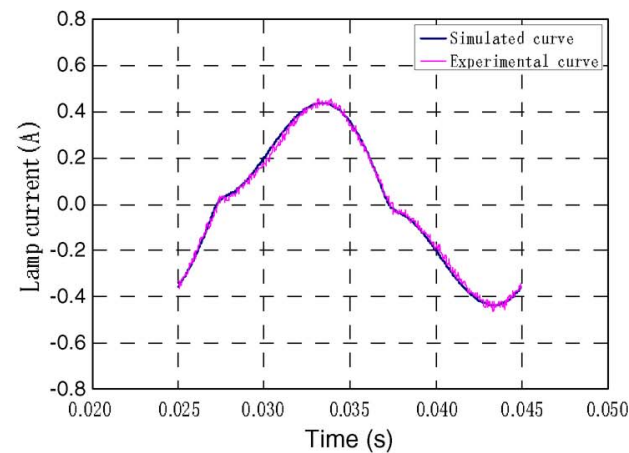

(b)

Fig. 13. Simulated and experimental lamp voltage and current waveforms of T8 36-W fluorescent lamp at 50-Hz operating frequency and $80 \%$ of rated lamp power. (a) Simulated and experimental lamp voltage waveforms. (b) Simulated and experimental lamp current waveforms.

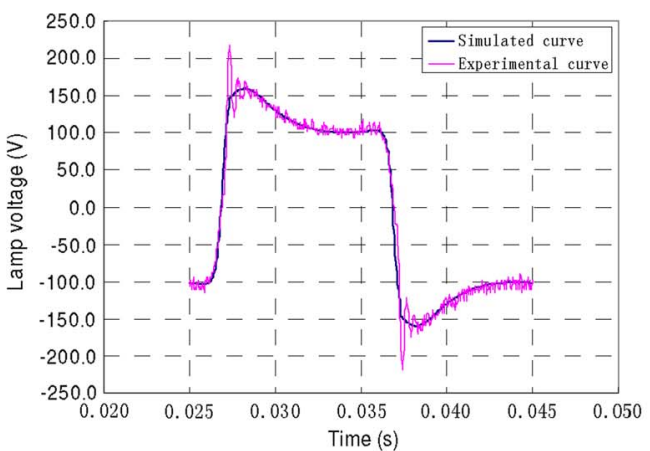

(a)

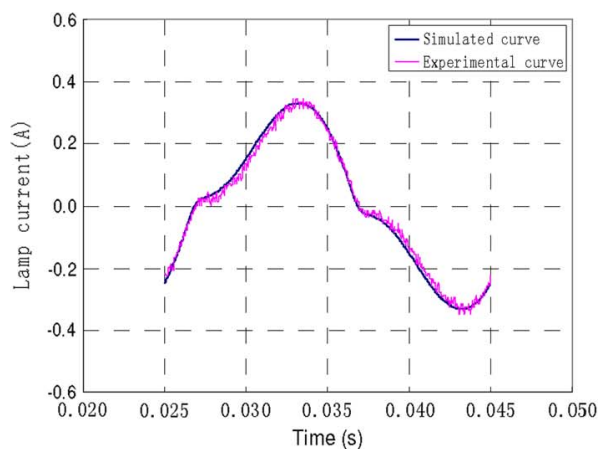

(b)

Fig. 14. Simulated and experimental lamp voltage and current waveforms of $\mathrm{T} 836-\mathrm{W}$ fluorescent lamp at 50-Hz operating frequency and $60 \%$ of rated lamp power. (a) Simulated and experimental lamp voltage waveforms. (b) Simulated and experimental lamp current waveforms.

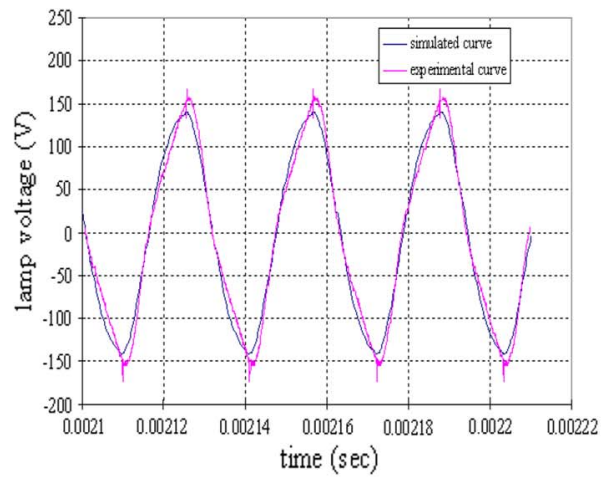

(a)

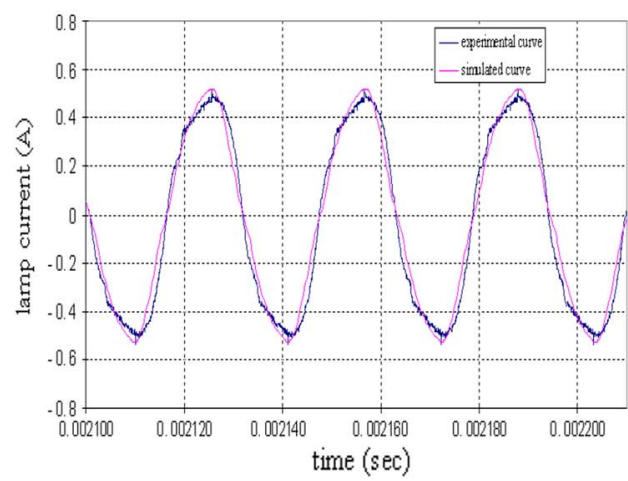

(b)

Fig. 15. Simulated and experimental lamp voltage and current waveforms of T8 36-W fluorescent lamp at 32-kHz operating frequency and $100 \%$ of rated lamp power. (a) Simulated and experimental lamp voltage waveforms. (b) Simulated and experimental lamp current waveforms. 


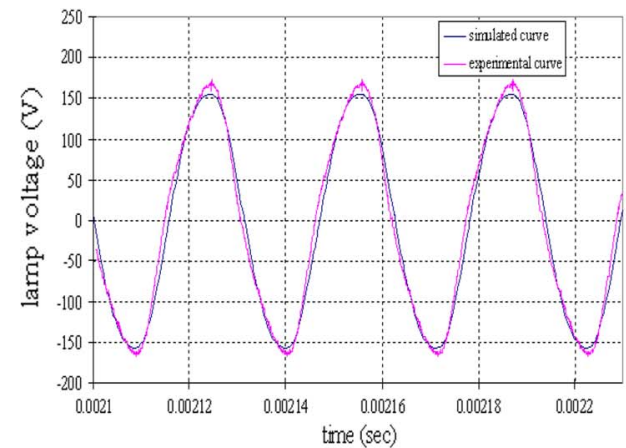

(a)

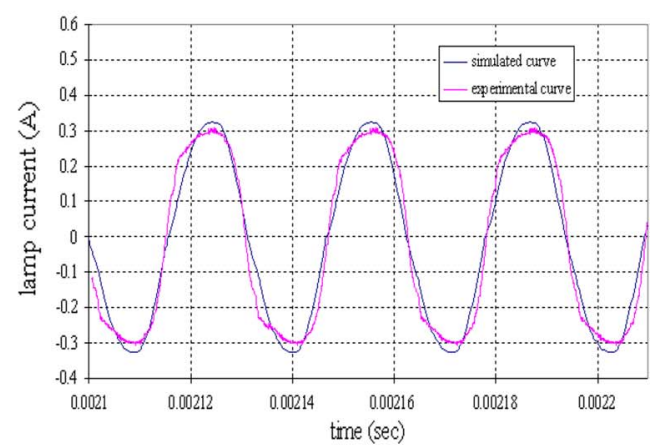

(b)

Fig. 16. Simulated and experimental lamp voltage and current waveforms of T8 36-W fluorescent lamp at 32-kHz operating frequency and 70\% of rated lamp power. (a) Simulated and experimental lamp voltage waveforms. (b) Simulated and experimental lamp current waveforms.

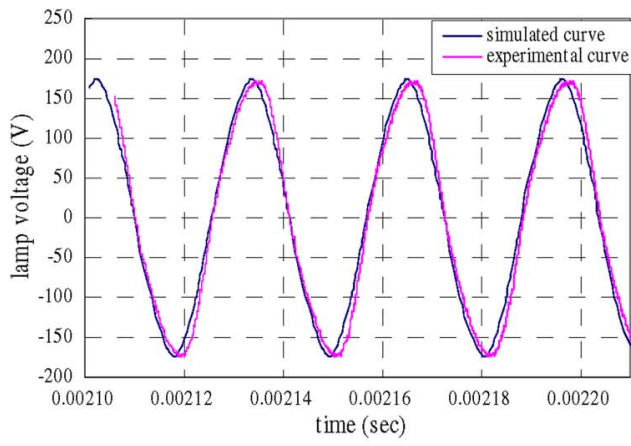

(a)

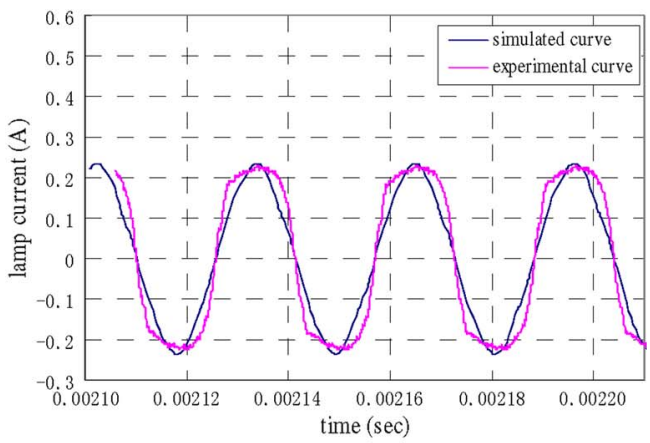

(b)

Fig. 17. Simulated and experimental lamp voltage and current waveforms of T8 36-W fluorescent lamp at 32-kHz operating frequency and $45 \%$ of rated lamp power. (a) Simulated and experimental lamp voltage waveforms. (b) Simulated and experimental lamp current waveforms.

of the ballast is a constant value and remains linear at any lamp power. These two possible reasons may affect the accuracy of the lamp model when it is applied to the critical reignition condition for both low- and high-frequency operation. In the future work, further improvement should be done in these areas.

\section{REFERENCES}

[1] H. S. H. Chung, N. M. Ho, W. Yan, P. W. Tam, and S. Y. Hui, "Comparison of dimmable electromagnetic and electronic ballast systems-An assessment on energy efficiency and lifetime," IEEE Trans. Ind. Electron., vol. 54, no. 6, pp. 3145-3154, Dec. 2007.

[2] H. S. Kim and T. J. Nam, "Saving power by discharge lamps with high efficient magnetic ballast," in Proc. Power Electron. Drives Energy Syst. Ind. Growth., Dec. 1998, vol. 2, pp. 700-704.

[3] K. H. Loo, D. A. Stone, and R. C. Tozer, "Modeling the electrical behavior of fluorescent lamps on the basis of a self-consistent collisionalradiative model," in Conf. Rec. IEEE IAS Annu. Meeting, Oct. 2004, vol. 3, pp. 1646-1654.

[4] M. Sun and B. L. Hesterman, "PSpice high-frequency dynamic fluorescent lamp model," IEEE Trans. Power Electron., vol. 13, no. 2, pp. 261272, Mar. 1998

[5] Y.-Z. Zhou, D.-Q. Guo, and Y.-J. Sun, "Simulation on electronic ballast for high intensity discharge lamps by PSIM," in Proc. 11th Int. Symp. Sci. Technol. Light Sources, Shanghai, China, May 20-24, 2007, pp. 69-70.

[6] S. Ben-Yaakov, "Modeling the high-frequency behavior of a fluorescent lamp: A comment on 'A PSpice circuit model for low-pressure gaseous discharge lamps operated at high frequency'," IEEE Trans. Ind. Electron., vol. 45, no. 6, pp. 947-950, Dec. 1998

[7] S. Ben-Yaakov, M. Shvartsas, and J. Lester, "A behavioral SPICE compatible model of an electrodeless fluorescent lamp," in Proc. 17th Аnnи. IEEE Appl. Power Electron. Conf., 2002, vol. 2, pp. 948-954.

[8] T.-F. Wu, J.-C. Hung, and T.-H. Yu, "A PSpice circuit model for lowpressure gaseous discharge lamps operated at high frequency," IEEE Trans. Ind. Electron., vol. 44, no. 3, pp. 428-431, Jun. 1997.

[9] C. S. Moo, Y. C. Hsieh, H. C. Yen, and C. R. Lee, "Fluorescent lamp model with power and temperature dependence for high-frequency elec- tronic ballasts," IEEE Trans. Ind. Appl., vol. 39, no. 1, pp. 121-127, Jan./Feb. 2003.

[10] J. L. Tapia Fabela, J. O. Pacheco-Sotelo, M. Pacheco Pacheco, J. S. Benitez-Read, R. Lopez-Callejas, G. Zissis, and S. Bhosle, "Electrical model for HPS discharge based on the energy-balance equation," IEEE Trans. Plasma Sci., vol. 35, no. 3, pp. 637-643, Jun. 2007.

[11] K. Erenturk, "Dynamic characterization of a UV fluorescent lamp," IEEE Trans. Plasma Sci., vol. 36, no. 2, pp. 519-523, Apr. 2008.

[12] C. Blanco, J. C. Anton, A. Robles, F. J. Ferrero, J. C. Campo, M. Gonzalez, and G. Zissis, "A discharge lamp model based on lamp dynamic conductance," IEEE Trans. Power Electron., vol. 22, no. 3, Part Special Section on Lighting Applications, pp. 727-734, May 2007.

[13] G. W. Chang and Y. J. Liu, "A new approach for modeling voltage-current characteristics of fluorescent lamps," IEEE Trans. Power Del., vol. 23, no. 3, pp. 1682-1684, Jul. 2008.

[14] L. Chhun, P. Maussion, S. Bhosle, and G. Zissis, "Interpolation modeling of acoustic resonance in high pressure sodium lamp," in Proc. 34th IEEE IECON, Nov. 10-13, 2008, pp. 1974-1979.

[15] G. G. Lister, V. A. Sheverev, and D. Uhrlandt, "Approximations to the electron energy distribution and positive column models for low pressure discharge light sources," J. Phys. D, Appl. Phys., vol. 35, no. 20, pp. 25862593 , Oct. 2002

[16] M. Cevi, A. R. Seidel, F. E. Bisogno, and R. N. Prado, "Fluorescent lamp model based on the equivalent resistance variation," in Conf. Rec. 37th IEEE IAS Annu. Meeting, Oct. 13-18, 2002, vol. 2, pp. 1489-1493.

[17] S. Ben-Yaakov, M. Shvartsas, and S. Glozman, "Statics and dynamics of fluorescent lamps operating at high frequency: Modeling and simulation," IEEE Trans. Ind. Appl., vol. 38, no. 6, pp. 1486-1492, Nov./Dec. 2002.

[18] K. H. Loo, D. A. Stone, R. C. Tozer, and R. Devonshire, "A dynamic conductance model of fluorescent lamp for electronic ballast design simulation," IEEE Trans. Power Electron., vol. 20, no. 5, pp. 1178-1185, Sep. 2005.

[19] P. Zhu and S. Y. R. Hui, "Modeling of a high-frequency operated fluorescent lamp in an electronic ballast environment," Proc. Inst. Elect. Eng.-Sci., Meas. Technol., vol. 145, no. 3, pp. 111-116, May 1998.

[20] Y. Wei, E. Tam, and S. Y. Hui, "A semi-theoretical fluorescent lamp model for time-domain transient and steady-state simulations," IEEE Trans. Power Electron., vol. 22, no. 6, pp. 2106-2115, Nov. 2007. 
[21] W. Yan, S. Y. R. Hui, and H. Chung, "Nonlinear high-intensity discharge lamp model including a dynamic electrode voltage drop," Proc. Inst. Elect. Eng.-Sci., Meas. Technol., vol. 150, no. 4, pp. 161-167, Jul. 2003.

[22] W. Yan, S. Y. R. Hui, H. Chung, and X. H. Cao, "Genetic algorithm optimized high-intensity-discharge lamp model," Electron. Lett., vol. 38, no. 3, pp. 110-112, Jan. 2002.

[23] A. I. Pressman, "High-frequency power sources for fluorescent lamps," in Switching Power Supply Design, 2nd ed. New York: McGraw-Hill, p. 575.

[24] D. Y. Lin, W. Yan, S. Hui, and Y. X. Qin, "An improved semi-theoretical fluorescent lamp model for dimmable applications," in Proc. 24th Annu. IEEE Appl. Power Electron. Conf., 2009, pp. 819-825.

[25] T.-E. Jang, H.-J. Kim, and H. Kim, "Dimming control characteristics of electrodeless fluorescent lamps," IEEE Trans. Ind. Electron., vol. 56, no. 1, pp. 93-100, Jan. 2009.

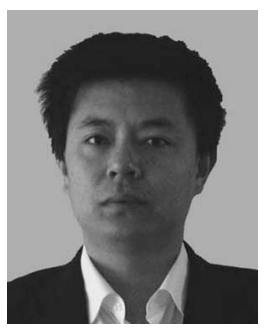

Deyan Lin (M'09) was born in China, in 1972. He received the B.Sc. and M.A.Sc. degrees in electrical engineering from the Huazhong University of Science and Technology, Wuhan, China, in 1995 and 2004, respectively. He is currently working toward the Ph.D. degree in the Department of Electronic Engineering, City University of Hong Kong, Kowloon, Hong Kong.

$\mathrm{He}$ is currently a Lecturer with Jianghan University, Wuhan, where he was an Assistant in the Electrical Engineering Department from 1995 to 1999. Since 2008, he has been a Senior Research Assistant with the City University of Hong Kong. His current research interests include the modeling, control, and simulation of gas-discharge lamps.

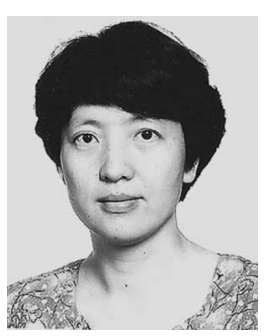

Wei Yan (M'97) received the B.Sc. and M.A.Sc. degrees in electrical engineering from the Huazhong University of Science and Technology, Wuhan, China, in 1982 and 1988, respectively, and the Ph.D. degree in electrical engineering from the University of Toronto, Toronto, ON, Canada, in 1996.

She is currently a Senior Research Fellow with the Department of Electronic Engineering, City University of Hong Kong, Kowloon, Hong Kong. Her research interests include gas discharge modeling and applications, computer-aided simulation techniques, lighting science, and power electronics applications.

Dr. Yan was the recipient of the Grand Applied Research Excellence Award in 2001 from the City University of Hong Kong and the Best Paper Award from the Production and Application of Light Committee in the IEEE Intelligent Autonomous Systems 2002 Annual Conference.

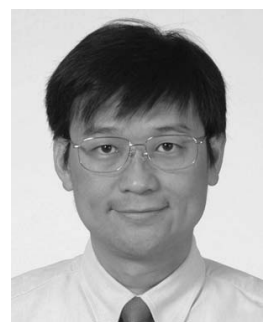

S. Y. (Ron) Hui (F'03) received the B.Sc.(Hons.) degree (Eng.) from the University of Birmingham, Birmingham, U.K., in 1984, and the D.I.C. and Ph.D. degrees from the Imperial College of Science and Technology, London, U.K., in 1987.

$\mathrm{He}$ was a Lecturer with the University of Nottingham, Nottingham, U.K., in 1987-1990. In 1990, he was with the University of Technology Sydney, Sydney, Australia, and was appointed Senior Lecturer at the University of Sydney, Sydney, in 1992, where he became a Reader in 1995. He joined the City University of Hong Kong (CityU), Kowloon, Hong Kong, as a Professor in 1996 and was promoted to Chair Professor in 1998. In 2001-2004, he served as an Associate Dean of the Faculty of Science and Engineering, CityU. From 2010, he holds the Chair Professorship at both the CityU and Imperial College London, London. He has published over 200 technical papers, including more than 140 refereed journal publications and book chapters. Over 45 of his patents have been adopted by industry.

Dr. Hui is a Fellow of The Institution of Engineering and Technology (IET). He has been an Associate Editor of the IEEE TRANSACTIONS ON POWER ELECTRONICS since 1997 and an Associate of the IEEE TRANSACTIONS ON INDUSTRIAL ELECTRONICS since 2007. He has been recognized twice as an IEEE Distinguished Lecturer by the IEEE Power Electronics Society in 2004 and 2006. He served as one of the 18 Administrative Committee members of the IEEE Power Electronics Society and was the Chairman of its Constitution and Bylaws Committee from 2002-2010. He was the recipient of the Teaching Excellence Award at CityU in 1998 and the Earth Champion Award in 2008. He was the recipient of the IEEE Best Paper Award from the IEEE Industry Applications Society Committee on Production and Applications of Light in 2002 and two IEEE Power Electronics Transactions Prize Paper Awards for his publication on wireless battery charging platform technology in 2009 and for his paper on LED system theory in 2010. His inventions on wireless charging platform technology underpin the dimensions of the international standard "Qi" for the wireless charging of consumer electronics with free-positioning, localized charging and load identification features. In November 2010, he was the recipient of the IEEE Rudolf Chope R\&D Award from the IEEE Industrial Electronics Society and the IET Achievement Medal (The Crompton Medal) and was elected to the Fellowship of the Australian Academy of Technological Sciences and Engineering. 